\title{
Important physico-chemical parameters and sediment characteristics of some selected sites in the Jaffna estuary
}

\author{
K Sivashanthini ${ }^{1}$, S Sutharshiny ${ }^{1 *}$, K Gunaalan ${ }^{1}$, A Tharmine ${ }^{1}$, \\ K Veronika², K M D Senathera digamadulla ${ }^{1}$ \\ ${ }^{1}$ Department of Fisheries, Faculty of Science, University of Jaffna, \\ ${ }^{2}$ Marine Environment Protection Authority, Kachcheri, Jaffna
}

\begin{abstract}
The present study was carried out to investigate the spatial variation of physico - chemical parameters and sediment characteristics in some areas of the Jaffna estuary in order to assess the differences among sites with respect to the measured parameters. A total of 29 stratified samplings were made on a fortnightly basis from October 2013 to April 2014. Surface water samples were collected along the selected GPS 12 Channel and physico-chemical parameters and bottom characteristics were also measured. Estuary depths increased significantly $(\mathrm{p}<0.05)$ from 40 to $770 \mathrm{~cm}$ at Nagathevanthurai, Pooneryn and Mandaitivu I respectively though water temperature was not significantly different. Salinity values were significantly $(\mathrm{p}<0.05)$ different with a wide range having $60 \mathrm{ppt}$ at Chavakachcheri while it was $32 \mathrm{ppt}$ in Mandaitivu IV. Water $\mathrm{pH}$ was alkaline at most of the sampling sites. Minimum value of electrical conductivity was recorded in Mandaitivu I as $15.56 \mathrm{mS} / \mathrm{cm}$ and the electrical conductivity value at Ketpali was $29.50 \mathrm{mS} /$ $\mathrm{cm}$. The turbidity range was between $12.64-48.50 \mathrm{~g} / \mathrm{L}$ with the lowest values at Velanai I (Allaipitty) and significantly $(\mathrm{p}<0.05)$ higher values were recorded at Kachchai. The dissolved oxygen concentration measured at Velanai III (Chettypullam) was significantly $(\mathrm{p}<0.05)$ high $(12.47 \mathrm{mg} / \mathrm{L})$ and the lowest value was recorded at Pooneryn II (Poovarasamtheevu), which was $7.00 \mathrm{mg} / \mathrm{L}$. Percentage of organic matter in the Kakkaitheevu I (Madaaruku) and Mandaitivu I ranged between 1.04 and 6.80 respectively. Percentage of silt - mud was followed by sand were the prominent sediment features in the Jaffna estuary. Results of the present study emphasize the spatial heterogeneity of physico-chemical and bottom characteristics in the Jaffna estuary.
\end{abstract}

Key words: Bottom characteristics, Jaffna Estuary, Physico-chemical parameters

\section{Introduction}

Marine water quality and sediment characteristics are a health index of marine ecosystems and provide nutritional balance among the marine living resources. Water quality parameters assessed by its physical, chemical and biological characteristics give background information about the nature of water. Physico - chemical parameters of the aquatic medium are important

* Correspondence : sutharshiny12@gmail.com 
aspects for the success of aquaculture operations. Jaffna estuary is a shallow water body with extensive mudflats, sea grass beds and mangroves located in the Northern Sri Lanka between $9^{0} 35^{\prime}$ $\mathrm{N}$ and $80^{\circ} 15^{\prime} \mathrm{E}$. The barrier-built, seasonally hypersaline estuary complex in the Jaffna Peninsula is the largest estuary system in the country with multiple perennial entrances showing extremely narrow salinity ranges towards the upper limit of salinity (Silva et al., 2013).

This estuary historically has a high economic rating due to fisheries activities. Coastal estuaries located between the land and the sea are heterogeneous complex ecosystems having different characteristics, while playing an important economic role, enriched by both the marine and continental inputs and are among the most productive aquatic ecosystems (Crossland et al., 2005). Saline water in the Jaffna estuary had been receiving a significant amount of pollutants from a variety of sources such as the hospital, dumping sites at coastal areas, hotels, hostels and toilet flushings from houses and commercial industries. The ecology of the estuary is determined to a large extent by freshwater inputs (Postma, 1981; Ittkoot et al., 2000). Spatial and temporal variations of the physico-chemical parameters in the estuaries of Sri Lanka have been analysed by several authors (Sachithananthan, 1969; Sachithananthan and Perera, 1970; Sivalingam, 2005; Niroshana et al., 2013).
The present study emphasises the spatial variation of water quality parameters in the Jaffna estuary in order to assess the differences among sites with respect to the measured parameters.

\section{Materials and Methods}

The present study was carried out at the Jaffna estuary (Figure 1) from October 2013 to April 2014. A total of 29 stratified samplings were made on a fortnightly basis. Name of the sampling locations are listed in the Table 1. A small fiber glass boat was hired to visit sampling sites. The boat was anchored randomly at different sampling sites and the respective locations were noted using a portable Global Positing System (GPS) (Garmin, Olathi, USA).

\section{Water quality parameters:}

Water samples were collected from the surface water in each location. Physico-chemical parameters such as depth, water temperature, salinity, water $\mathrm{pH}$, electric conductivity, turbidity and dissolved oxygen were measured using portable instruments. Depth of the water (in cm) was determined by lowering a rope which is tied up with a weight. Water temperature $\left({ }^{0} \mathrm{C}\right)$, electric conductivity $(\mathrm{mS} / \mathrm{cm})$ and turbidity $(\mathrm{g} / \mathrm{L})$ were measured by a multi-parameter meter (Sension MM 150/ Hach, Crison instruments, S.A). Salinity was estimated using a refractometer (Atago, S/Mill-E, Japan). pH of water was measured directly by a digital electronic $\mathrm{pH}$ meter (Eco Testr). Dissolved oxygen $(\mathrm{mg} / \mathrm{L})$ was measured by Winkler's method (Winkler, 1888). 


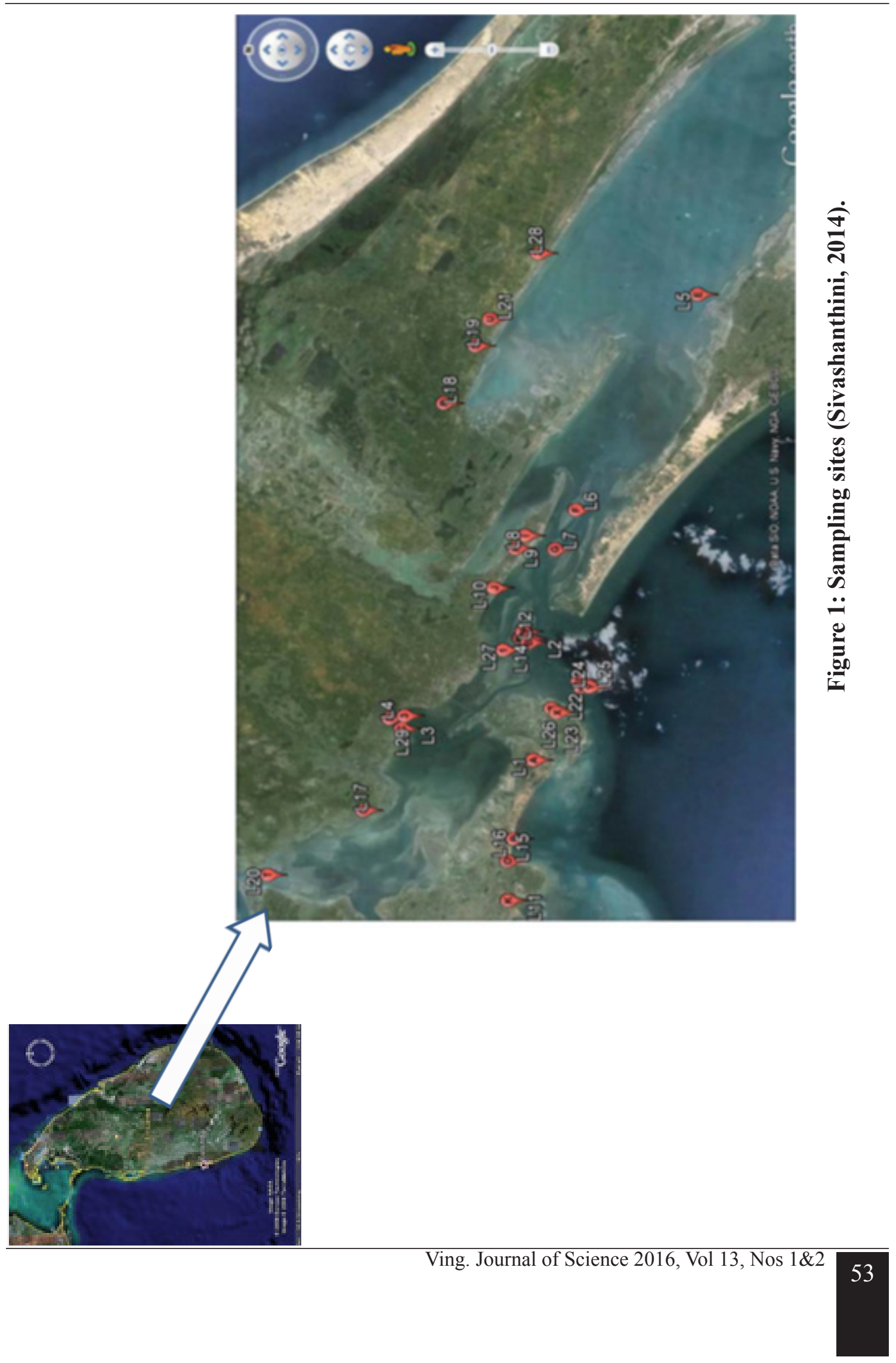




\section{Table 1: Name and number of the sampling locations}

\begin{tabular}{|l|l|l|l|}
\hline $\begin{array}{c}\text { Location } \\
\text { Number }\end{array}$ & \multicolumn{1}{|c|}{ Name of the Location } & $\begin{array}{l}\text { Location } \\
\text { Number }\end{array}$ & Name of the Location \\
\hline L1 & Velanai I (Allaipitty) & L16 & Velanai IV \\
\hline L2 & Kurunagar I (Kallady) & L17 & AralyThurai \\
\hline L3 & Kakkaitheevu I (Madaaruku) & L18 & Chavakachcheri \\
\hline L4 & Kakkaitheevu II (Irandmkaddai) & L19 & Kachchai \\
\hline L5 & Pooneryn I (Nagathevanthurai) & L20 & PonnalaiThurai \\
\hline L6 & Pooneryn II (Kowtharimunai) & L21 & Ketpali \\
\hline L7 & Pooneryn III (Poovarasamtheevu) & L22 & Mandaitivu I \\
\hline L8 & Ariyalai I & L23 & Mandaitivu II \\
\hline L9 & Ariyalai II (Poompuhar) & L24 & Mandaitivu III \\
\hline L10 & Ariyalai III (Poompuhar) & L25 & Mandaitivu IV \\
\hline L11 & Velanai II (Allaipitty) & L26 & Mandaitivu V \\
\hline L12 & Kurunagar II (Kallady) & L27 & $\begin{array}{l}\text { Kurunagar - Mugath- } \\
\text { uvaram }\end{array}$ \\
\hline L13 & Kurunagar III (Mannithalai) & L28 & Vidaththalpalai \\
\hline L14 & Kurunagar IV (Vajiruveenki) & L29 & Navanthurai \\
\hline L15 & Velanai III (Chettypullam) & & \\
\hline
\end{tabular}

\section{Sediment characteristics:}

Organic matter and grain size analysis were carried out in order to characterize the various sediment structures at all selected sites. Sediment samples were collected using Ekman grab sampler and dried in an oven (YCO-010, Taiwan) at $60^{\circ} \mathrm{C}$ for 72 hours. A sample of dried sediment was sieved using a soil sieve set (Seichess, UK) with sieves spanning from $0.0039 \mathrm{~mm}$ to 64 $\mathrm{mm}$. To determine the organic matter, the dried sediment was weighed and charred in a muffle furnace (Muffle furnace - Navyug, India) for 4 hours at $500^{\circ} \mathrm{C}$ and then reweighed (Tsiresy et al., 2011). The organic matter was calculated as a percentage weight loss following combustion.

\section{Data Analysis:}

Statistical analysis for all the data was performed using SPSS 16 version. The data were checked for normal distribution with Shapiro-Wilk test. The means of physico-chemical parameters of the water samples from selected sites were compared by Kruskal-Wallis test.

\section{Results}

Figures 2 - 9 show the values of mean and standard deviation of the physico-chemical parameters of water collected from all the sampling sites.

Estuary depths significantly varied from 40 to $770 \mathrm{~cm}$ at Location 5 - Nagathevanthurai, Pooneryn and at Location 22 - Mandaithevu I respectively (Figure 2).

The value of water temperature did not show a significance $(\mathrm{p}<0.05)$ in the Jaffna estuary (Figure 3). Maximum value was recorded in 
Velanai I (Allaipity) (L1), which was $32^{\circ} \mathrm{C}$ while minimum value was recorded in Ponnalai (L20). Salinity demonstrated a significant difference $(\mathrm{p}<0.05)$ having a wide range of $60 \mathrm{ppt}$ at Chavakachcheri (L18) and the lowest values of 32 ppt at Mandaitivu IV (L26) (Figure 4).

Water $\mathrm{pH}$ was recorded mainly as alkaline, values ranging from 7.1 to 9.3 in all the sites other than at L9, L18, L19, L21, L22 and L25 (Figure 5). Lowest acidity $\mathrm{pH}$ values were observed at Ariyalai II (Poompuhar) (L9) and Mandaitheevu - III (L25) while pH of 7.0 was recorded at Chavakachcheri (L18), Kachcai (L19), Ketpali (L21) and Mandaitheevu - I (L22) (Figure 5).

In Mandaitivu I (L22), minimum value of electrical conductivity recorded as 15.56 and in the Ketpali (L21), the electrical conductivity value was $29.50 \mathrm{mS} / \mathrm{cm}$ (Figure 6).
The turbidity range was $12.64-48.50 \mathrm{~g} / \mathrm{L}$ with the lowest values registered at Velanai I (Allaipitty) (L1) and the highest value was recorded at Kachchai (L19) (Figure 7).

Dissolved oxygen concentration measured at Chettypullam - Velanai III (L15) was the highest $(12.47 \mathrm{mg} / \mathrm{L})$ and the lowest value was recorded at Poovarasamtheevu- Pooneryn II (L7), which was $7.00 \mathrm{mg} / \mathrm{L}$ (Figure 8).

Percentage of organic matter in the location 3 (Madaaruku - Kakkaitheevu I) and Location 23 (Mandaitivu I) ranged from 1.04 and 6.80 respectively (Figure 9).

Figure 10 shows the percentage of grain size of sediments in the sampled sites of the Jaffna estuary. Silt - mud followed by sand were the prominent sediment features (Figure 10). 


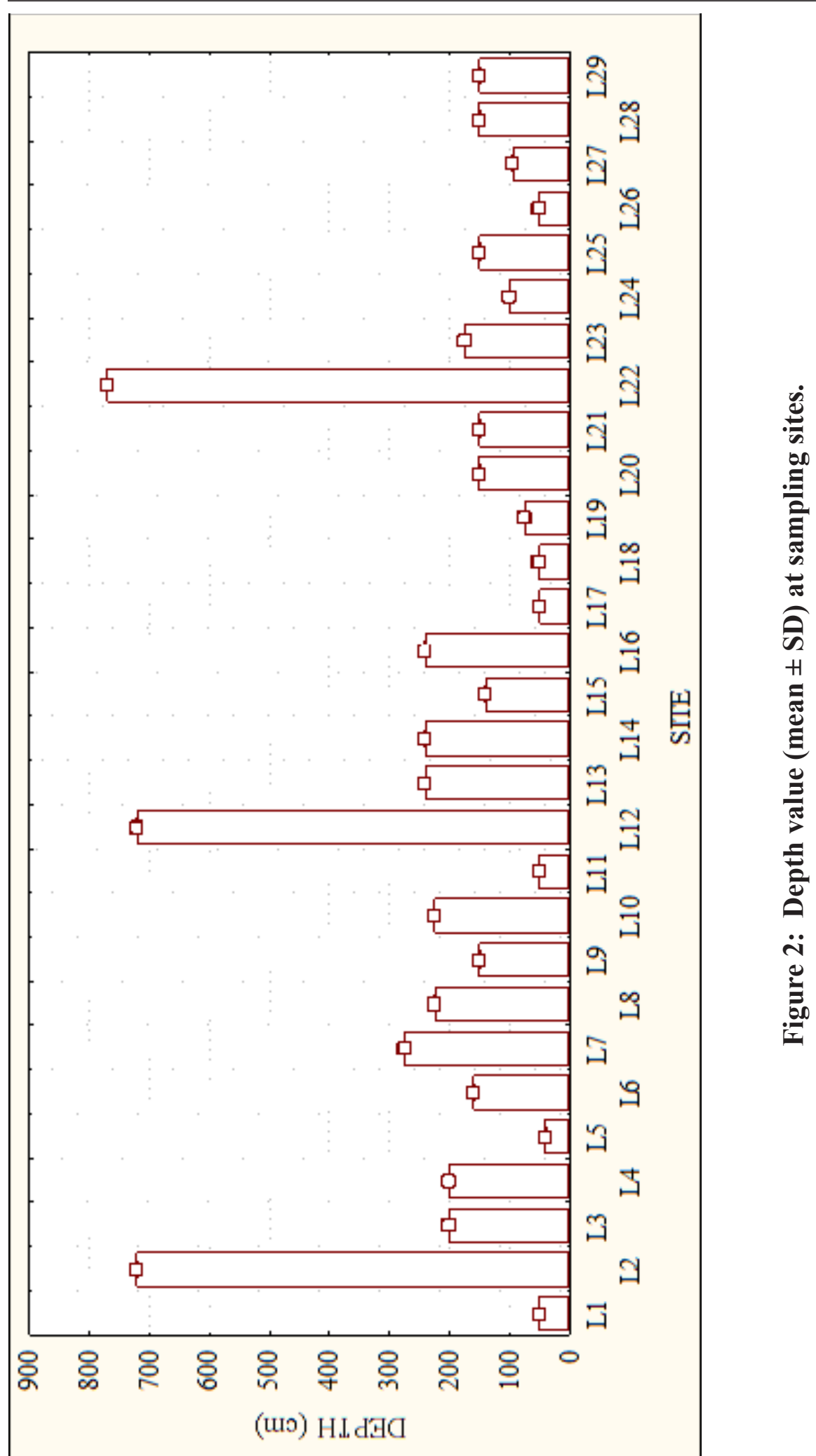

\section{6}




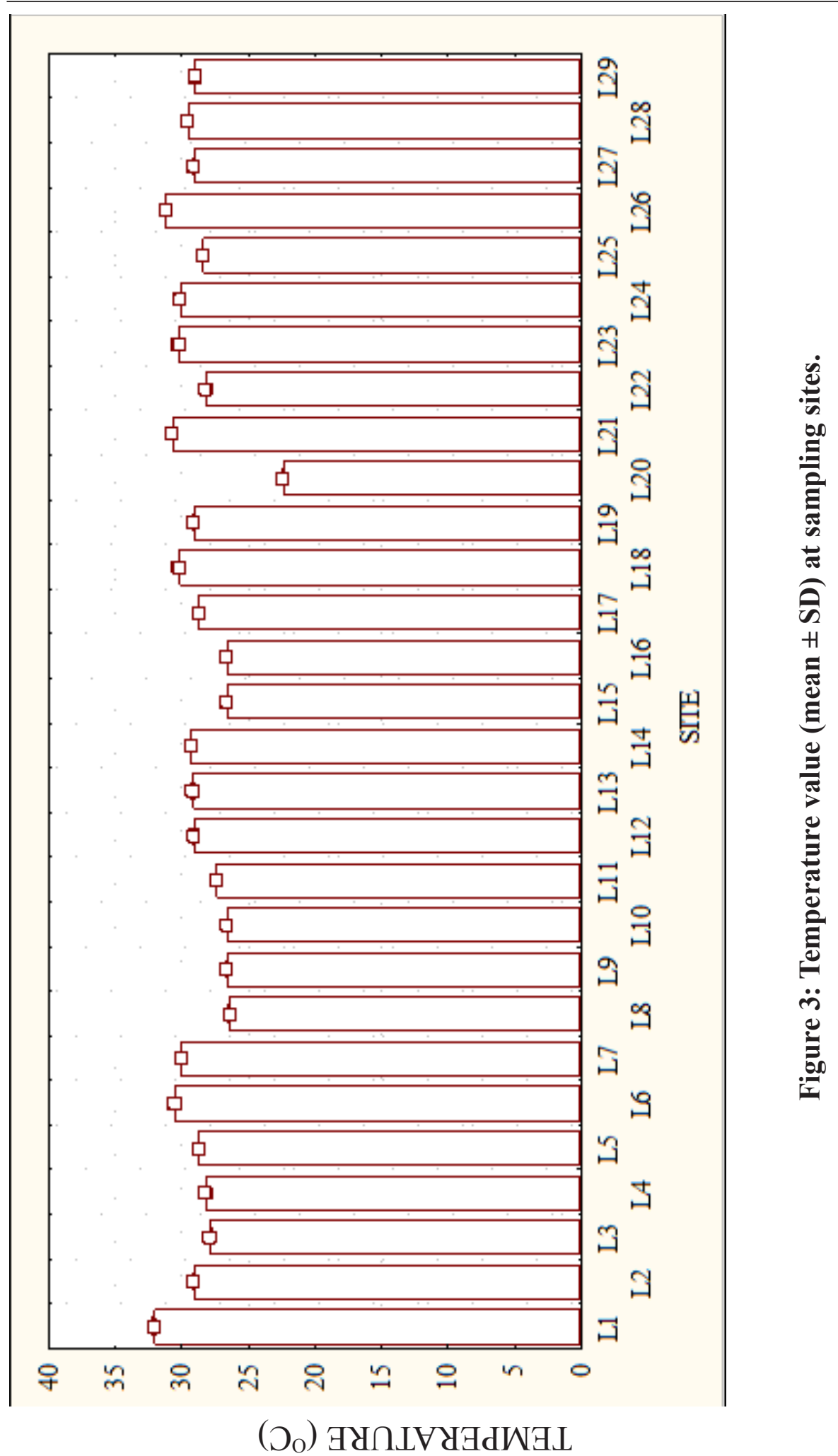

Ving. Journal of Science 2016, Vol 13, Nos 1\&2 


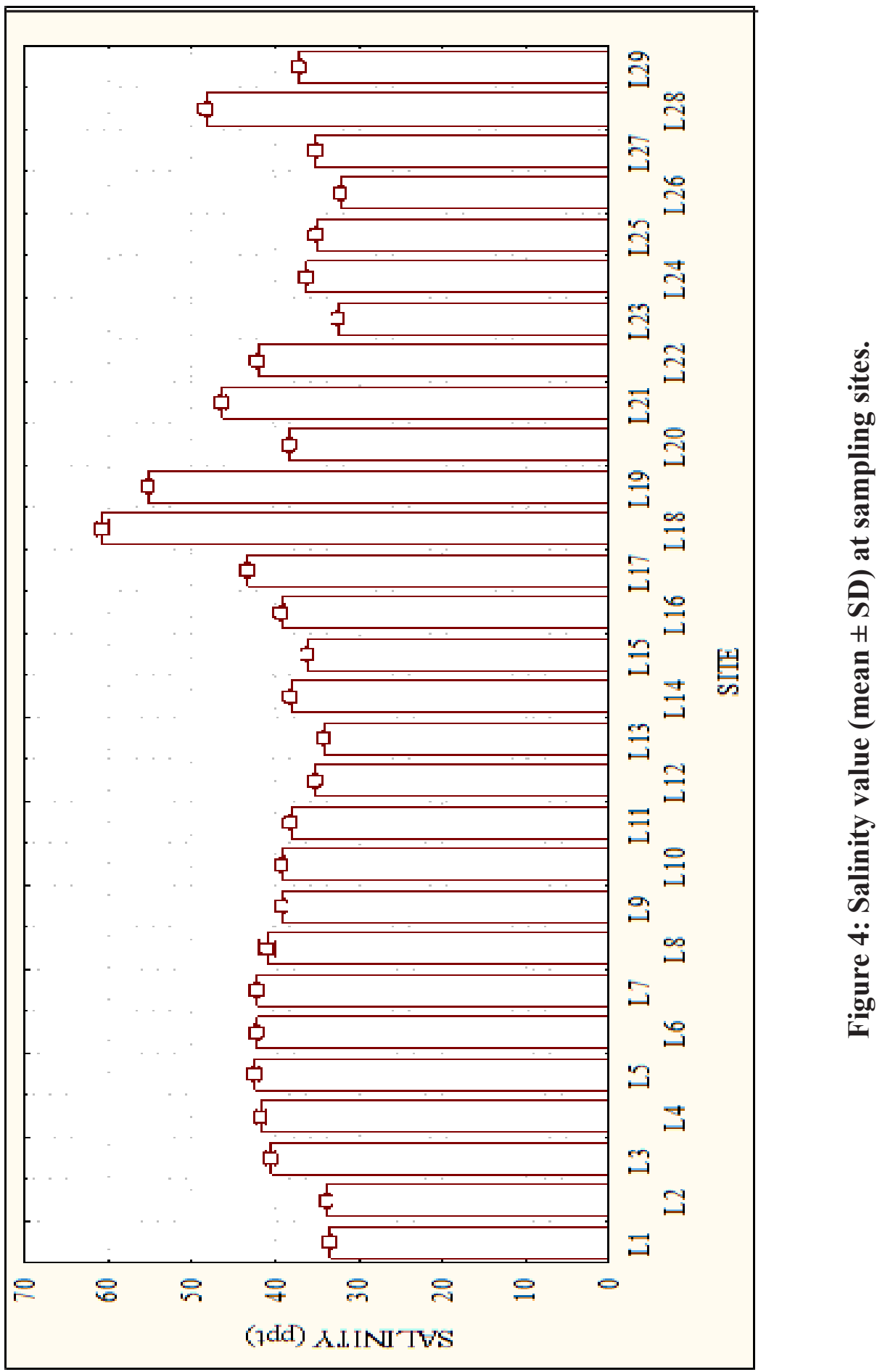

58

Ving. Journal of Science 2016, Vol 13, Nos 1\&2 


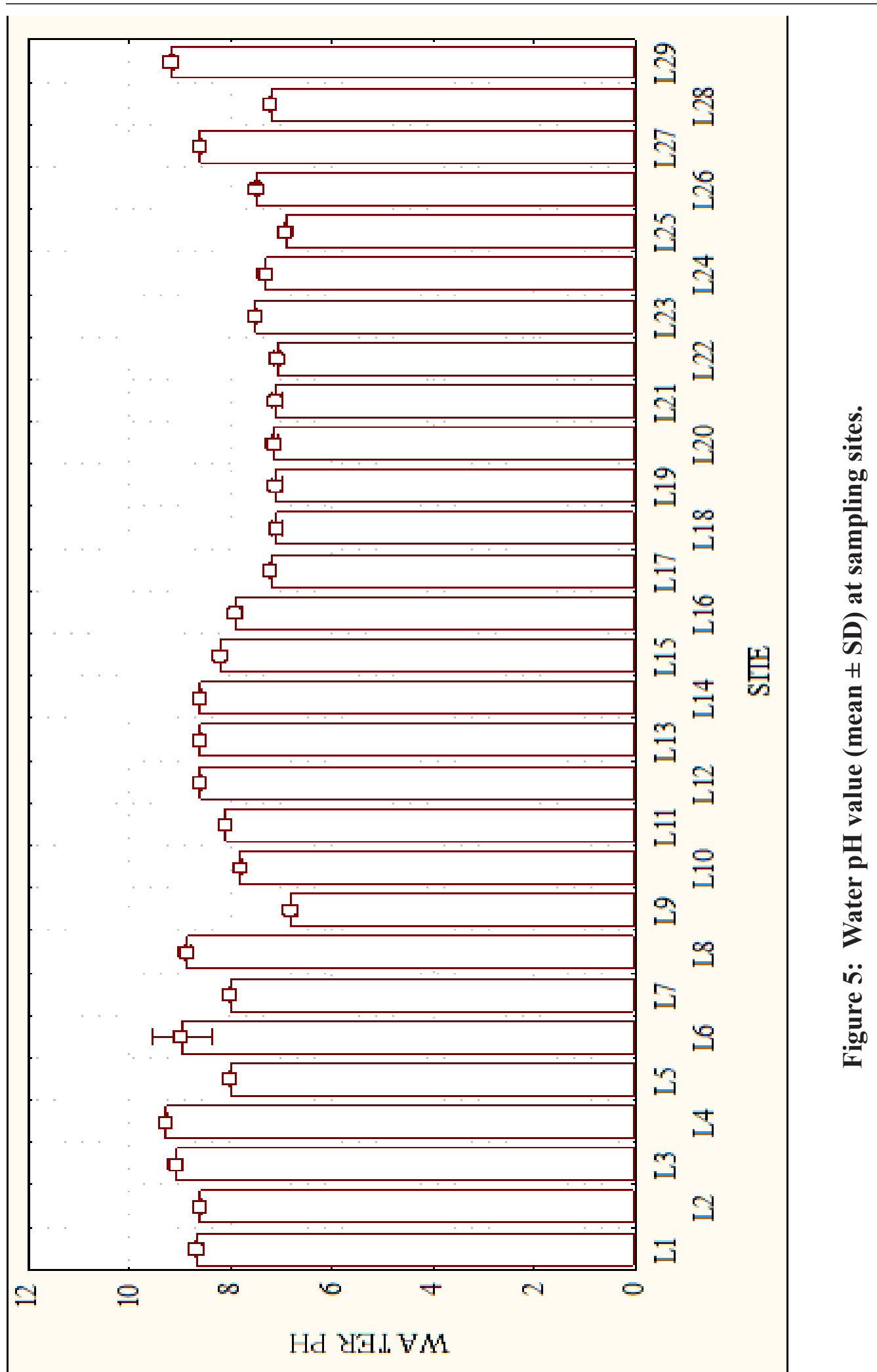




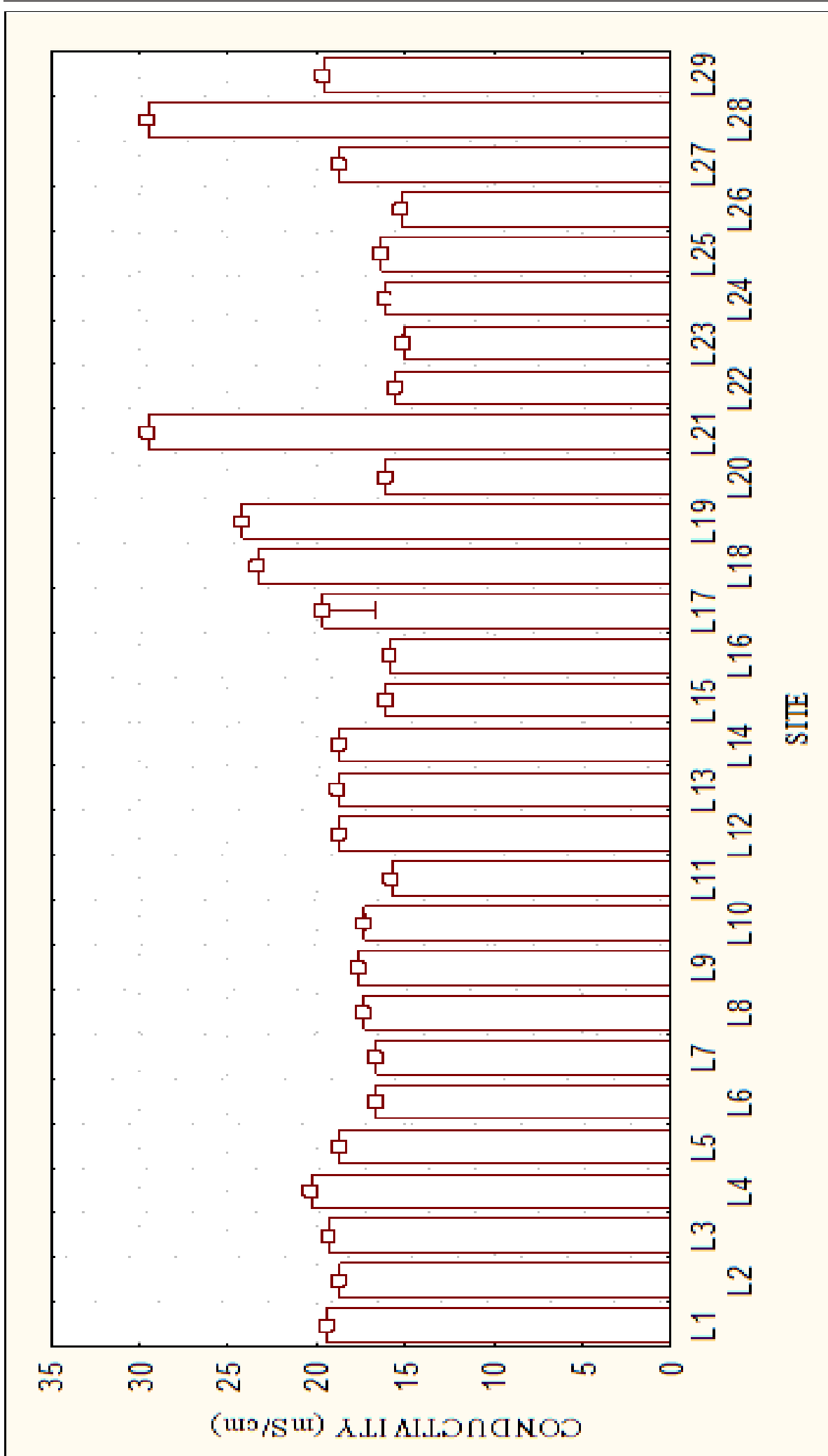

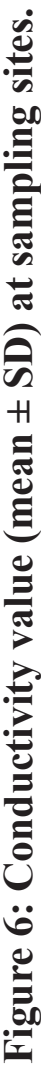




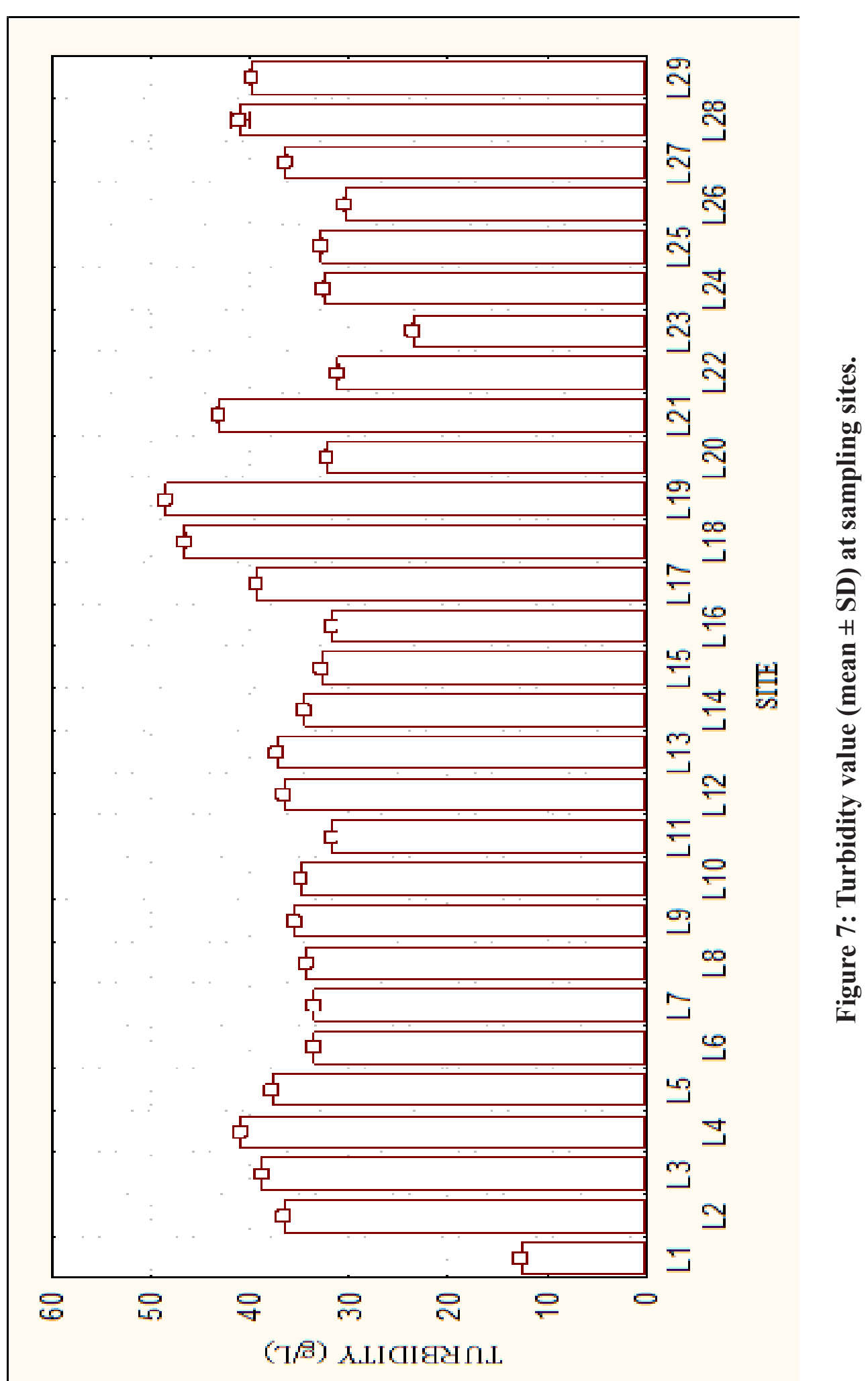




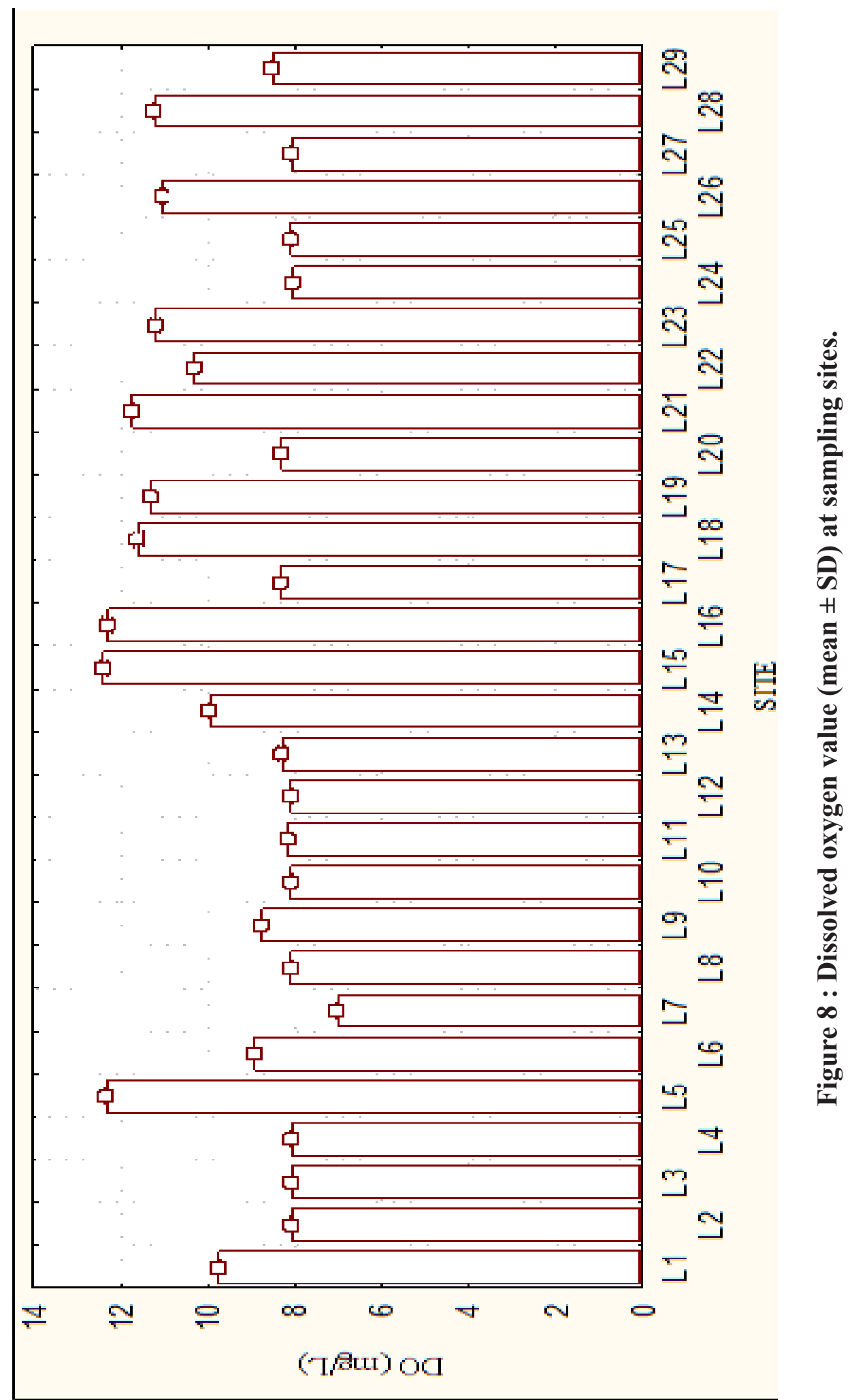

\section{2}

Ving. Journal of Science 2016, Vol 13, Nos 1\&2 


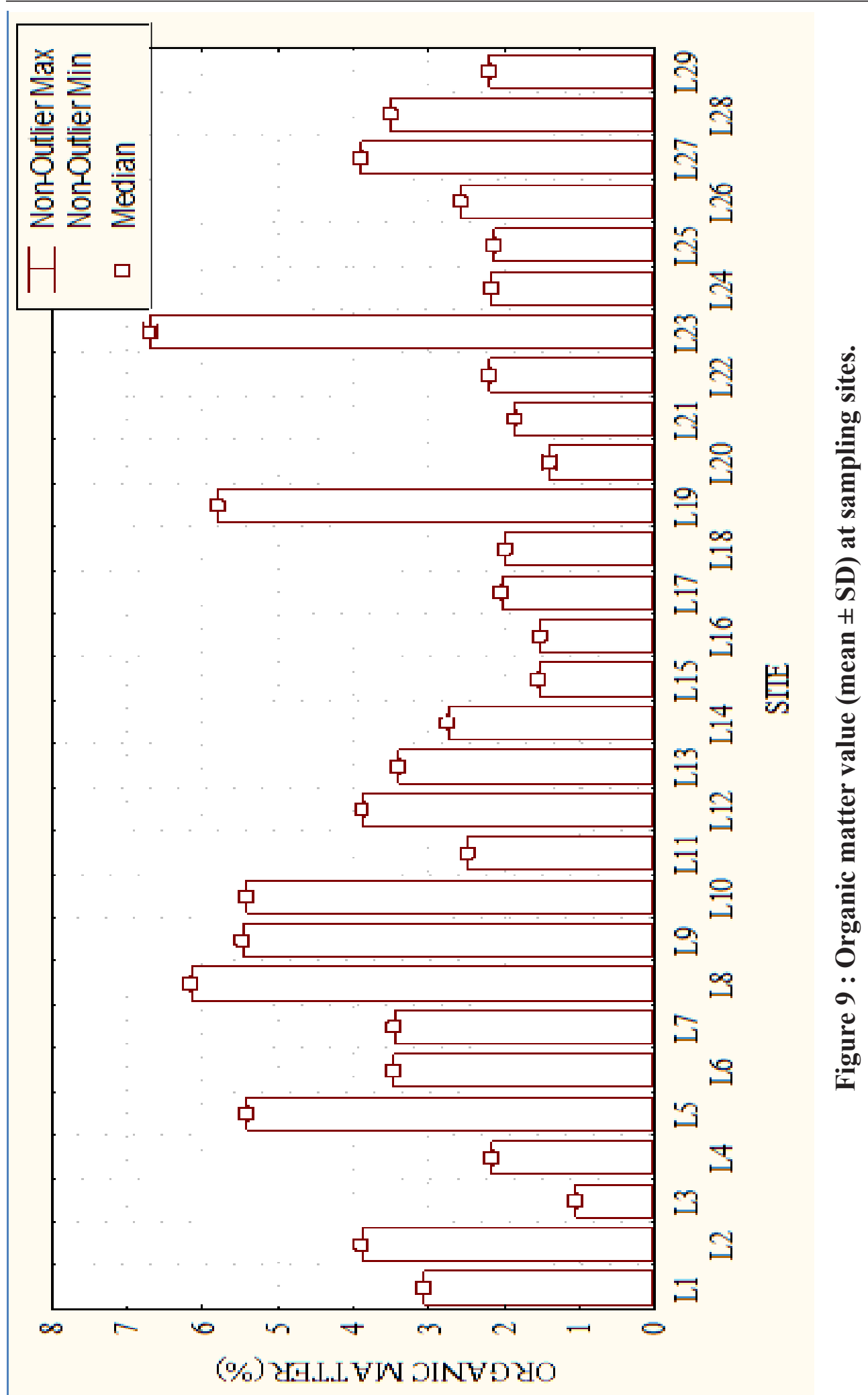




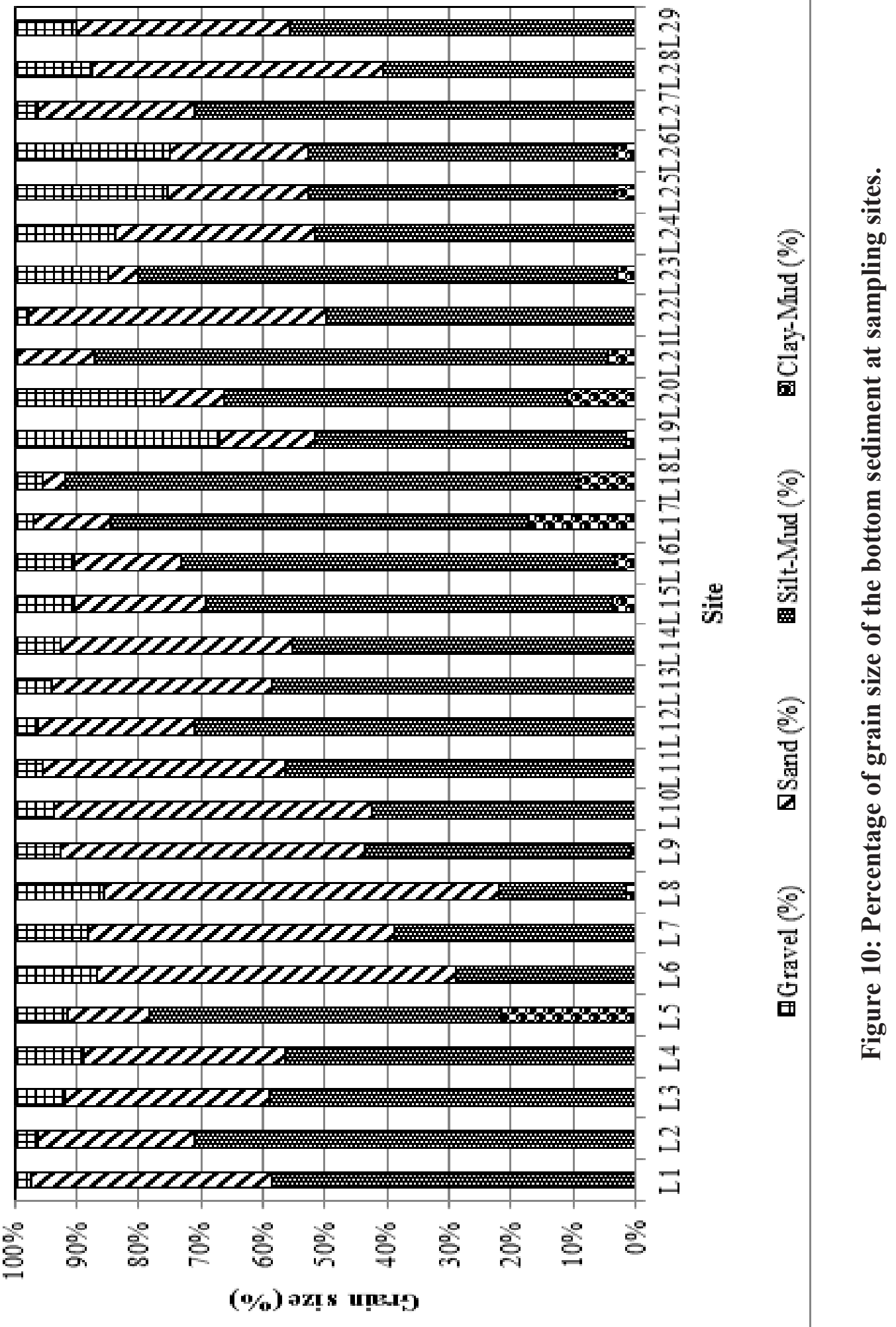




\section{Discussion}

There are limited studies on the physico-chemical and sediment characteristics of the Jaffna estuary. However, a wide range of estuary depths were recorded from 40 to $770 \mathrm{~cm}$ in the present study. Sachithananthan and Perera (1970) reported that the Jaffna estuary is very shallow and is navigable only through the few channels which are generally $3-5$ feet in depth.

The range of salinity recorded in the present study was from $32 \mathrm{ppt}$ to $60 \mathrm{ppt}$. Conversely, Sivalingam (2005) reported salinity values for wet season and dry season at some locations in the Jaffna estuary, which were $10.3 \mathrm{ppt}$ in December and $45.5 \mathrm{ppt}$ in June respectively. Sachithananthan (1969) also reported that the salinity of the Jaffna estuary varied from a maximum of $45.5 \mathrm{ppt}$ during July-August to a minimum of $10.4 \mathrm{ppt}$ during December. In the present study, the highest value of salinity presented at some sampling sites of the Jaffna estuary could be attributed to the low amount of rain fall and higher rate of evaporation. The spatial and diurnal patterns in salinity distribution in the Jaffna estuary being linked to oceanic currents of the Indian Ocean and freshwater flux from the north- central part of the island (Arudpragasam,1974).

Surface water temperature ranged from 22.4 to $32^{\circ} \mathrm{C}$ in the present study. Similar results reported by Sachithananthan (1969).

Organic content at the bottom of the Jaffna estuary showed low amount when compared with the studies of Sachithananthan and Perera (1970), authors recorded the range of organic matter in the Jaffna estuary with the lowest value (2.9\%) in coarse non-sticky mud and highest value
(16.1\%) in coarse sticky mud type. The lowest value of organic matter could be related to high recycling rates.

In the present study, percentage of silt - mud followed by sand was the prominent sediment feature in the Jaffna Estuary. Similar observations reported by Sachithananthan and Perera (1970) showed that the shoreline of the Estuary is sandy, the channels are muddy and the bottom is not firm. The findings obtained in the present study highlight wider fluctuations of physico chemical parameters and sediment features in the Jaffna Estuary. There are many factors influencing the fluctuations of water quality parameters and sediment characteristics such as geographical locations and anthropogenic activities. Based on the variability of the parameters in the Jaffna Estuary, the suitable culture sites for cultivable species such as shrimp, sea cucumber and seaweeds could be selected.

\section{Acknowledgement}

Authors are grateful to Mangroves for the Future, Colombo (Grant No: MFF/98) with Danida, Norad and Sida for the financial support.

\section{References}

Arudpragasam, K.D. (1974). Estuar. Coast. Mar. Sci. 2(3): 251-259.

Crossland, C.J., Kremer, H.H., Lindeboom, H.J., Marshall Crossland, J.I. and Le Tissier, M.D.A. (2005). Global Change - The IGBP Series no XX (Springer), 232pp.

Ittkoot, V., Humborg, C. and Schafer, P. (2000). Bio. Sci. 50: 776-782.

Niroshana, K.H.H., Asanthi, H.B. and Kumara, P.B.T.P. (2013). J.Univ.Ruhun, 1(1): 23-30. 
Postma, H. (1981). Unesco Tech. Pap. Mar. Sci. Sivalingam, S. (2005). J. Nat. Sci. Found. Sri. 33: 111-117. 33(4): 225-232.

Sachithananthan, K. (1969). Bull. Fish. Res. Stn., Sivashanthini, K. (2014) .University of Jaffna, Ceylon. 20: 87-99. Harikanan (Publish), 101pp.

Sachithananthan, K. and Perera, K. (1970) Bull. Fish. Res. Stn., Ceylon. 21: 75-85.

Tsiresy, G. Pascal, B. and Plotieau, T. (2011). SPC Beche-de-mer Information Bull. 31 : $17-22$.

Silva, E.I.L., Katupotha, J., Amarasinghe, O., Manthrithilake, H. and Ariyaratna, R. (2013). Winkler, L.W. (1888). Berichte der Deutschen Int. Water Management Institute, $122 \mathrm{pp}$. Chemischen Gesellschaft, 21: 2843-2855. 